\title{
Assessment of Taeniasis-Cysticercosis Status Using Multiple Laboratory Diagnostic Tools in Banti Village, Mimika, Papua
}

\author{
Helena Ullyartha Pangaribuan ${ }^{1^{*}}$, I Kadek Swastika ${ }^{2}$, Akira Ito $^{3}$, Darma Irawan ${ }^{4}$
}

\author{
${ }^{I}$ National Institute Health Research \& Development, Ministry of Health Republic Indonesia \\ ${ }^{2}$ Department of Parasitology Udayana University, Denpasar, Bali, Indonesia \\ ${ }^{3}$ Department of Parasitology Asahikawa Medical University, Hokkaido, Japan \\ ${ }^{4}$ PT Freeport Indonesia Hospital, Tembagapura, Papua, Indonesia \\ ${ }^{*}$ Corresponding Author. Email: helenartha@yahoo.co.uk
}

\begin{abstract}
PT Freeport Indonesia Hospital located in Tembagapura, District Mimika, Papua, reported three neurocysticercosis (NCC) suspected cases with acute symptomatic seizures, epilepsy and headaches in 2014. Computed tomography (CT) revealed multiple cystic lesions in the brain and disseminated cysticercosis in the leg. With national control program initiative, the assessment was conducted in 2015. This study aimed to understand the prevalence of $T$ solium taeniasis and cysticercosis among the community in Banti Village. Methods: A cross-sectional study was conducted in Banti Village. Each individual was questioned about taeniasis and their eating habit, and also provided fecal and blood samples. All fecal samples were examined for presence of Taenia spp eggs and soil-transmitted helminth (STH) eggs by Kato Katz technique, and serum samples were tested for specific IgG antibodies to T. solium cysticercus by an enzyme-linked immunosorbent assay (ELISA). Results: CT revealed three NCC cases with partially calcified, multiple cysts in the brain and one case was disseminated cysticercosis. Two of them were analyzed serologically. One was positive and the other was just under the cut-off value. A total of 132 local people was involved in the study. There was no Taenia egg positive. Moreover, $60.6 \%$ of them (80/132) were positive for eggs of STHs (Ascaris, Trichuris or hookworm). Fifteen of 131 people who were sero-negative showed relatively higher OD values close to the cut-off values. They should be followed up if they become positive or not. Eating raw pork warmed under hot stones, known as 'Bakar Batu', is traditional in Papua. Patients claimed that they continued this practice as an important part of their culture. This case report result is illustrative of the risk of veiled NCC associated with the habit of eating raw pork. These patients are regarded as indigenous as NCC cases of infected in Mimika District, Papua. Further studies towards control of NCC are an urgent task.
\end{abstract}

Keywords: assessment, taeniasis, cysticercosis, NCC

\section{INTRODUCTION}

Intestinal Taeniasis is caused by both $T$. solium and $T$ saginata. The part of taeniasis life cycle is human as definite host, pig as intermediate host and Cysticercus cellulosae (larva) as Infective stage. The infection is derived from consuming inadequately cooked pork containing cysticercus cellulosae (measly pork) and usually in persons of low socio-economic condition with poor sanitation. But cysticercosis may occur in any person residing in endemic areas, even in vegetarians because the mode of infection is contamination of food or drink with egg deposited in soil $[3,4,11,13,15]$.

Human cysticercosis is caused by larval stage (cysticecus cellulosae) of $T$. solium. Cysticercus cellulosae may be solitary or more often multiple. Any organ or tissue may be involved, the most common being subcutaneous tissues and muscles. It may also affect the eyes, brain, and less often the heart, liver, lungs, abdominal cavity, and spinal cord. The cysticercus is surrounded by a fibrous capsule except in the eye and ventricles of the brain. The larvae evoke a cellular reaction starting with infiltration of neutrophils, eosinophils, lymphocytes, plasma cells, and at times, giant cells. This is followed by fibrosis and death of the larva with eventual calcification. The clinical features depend on the site affected Subcutaneous nodules are mostly asymptomatic, Muscular cysticerosis may cause acute myositis, Neurocysticerosis (cysticercosis of brain) is the most common and most serious form of cysticercosis. About 70\% of adult-onset epilepsy is due to neurocysticercosis [4].

T. solium is disseminated around the world where swine are raised for human utilization. The recurrence has diminished in created nations owing to stricter meat review, superior cleanliness and superior clean offices. The dispersion of 
cysticercosis coincides with the dispersion of $T$. solium. In Ethiopia, Kenya and of the $10 \%$ population of the Democratic Republic of Congo infected, in Madagascar indeed $16 \%$ [10].

In Indonesia, Papua has recorded endemic for taeniasis/cysticercosis.[19] In 2014, Three suspected NCC patients were reported by PT Freeport Indonesia Hospital located in Tembagapura, District Mimika, Papua, with clinical sign; acute symptomatic seizures, epilepsy and

\section{METHOD}

One study village nearby the Tembaga Pura Hospital was selected to understand the prevalence of $T$ solium taeniasis and cysticercosis among the community in Banti Village. Banti itself is located at an altitude of approximately $1500 \mathrm{~m}$ above sea level. With this height the average reaches $15-18^{\circ} \mathrm{C}$ and is almost always foggy. The people of Papua who live in Banti are the moslty Amungme tribe, one of the largest tribes in Papua. Besides Amungme. The village is located 35,36 kilometers from Timika City, the capital city of Mimika District. Total Population of Banti village is approximately 3,000 people, most identifying with Christian faith where several pigs are raised, most of them left roaming.[9]

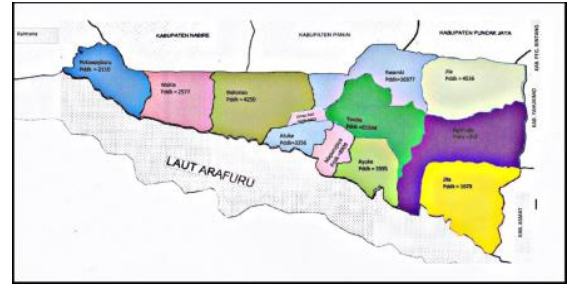

Figure 1. Map of Timika District [12]

The data were collected as part of a cross-sectional study on the microscopic and seroprevalence of Taniasis/cysticercosis and STH conducted September 2015. The sample size calculation was performed using a single proportion formula: $\mathrm{N}=\mathrm{P}(1-\mathrm{p}) \mathrm{Z} 2 / \mathrm{d} 2$, where $\mathrm{P}=$ prevalence of estimated neurocysticercosis from WHO (30\%), Z = level of confidence, 1.96 and $d=5 \%$ marginal error, which gave a minimum sample size of 108 peoples.

Stool samples were collected in Banti Village at least 108 samples aged 10 years and above this age group was particularly targeted because they are the most likely members of the community who could attend and actively participate in occasions where eating raw pork warmed under hot stones, known as 'Bakar Batu', is traditional in Papua. We distributed the stool container while implement health education to the community. The next day, stool and blood samples were collected for examination. Each of the subject was provided with a unique identification (ID) code to identify each individual and avoiding repetitive sampling. After collection of the whole blood, allow the blood to clot by leaving it undisturbed at room temperature. This usually takes 30 minutes and no more than an hour. Remove the clot by centrifuging at $1,000-2,000 \mathrm{x} \mathrm{g}$ for 10 minutes. The resulting supernatant is designated serum headaches. The Computed tomography (CT) revealed multiple cystic lesions in the brain and disseminated cysticercosis in the leg. Furthermore, the national program dispatches the team to investigate as a part of public health surveillance. The hospital located nearby Banti Village. Therefore, the assessment was conducted in Banti Village with objective to understand the prevalence of $T$ solium taeniasis and cysticercosis among the community in Banti Village.

The Kato-Katz technique (cellophane faecal thick smear) was employed for the determination of the level of intestinal Taenia solium ova/eggs and STH in collected stool samples. The infestation was determined by microscopically examining $41.7 \mathrm{mg}$ of faecal material and systematically counting the eggs in the faecal specimens. To increase the visibility of the parasite eggs, the cellophane was soaked in a $3 \%$ methylene blue for 24 hours before usage. For serum samples this methods using glycoprotein as ELISA antigens were prepared by cation-exchange chromatography from $T$. solium cyst fluid. The result was evaluated by ELISA plate reader using the optical density at $405 \mathrm{~nm}$ (OD405). The cut off value was set as the mean OD value plus $4 \mathrm{SD}$ of serum samples from 20 healthy human serum. To confirm that the ELISA was carried out appropriately, one positive control pooled serum sample from a confirmed human cysticercosis T. solium. This activity was part of the investigation and supervision of public health surveillance of the national program so the approval from Research Ethics Committee is not required but all assay follow procedures standard procedures and be subject to rigorous ethical assessment.

\section{RESULTS AND DISCUSSION}

\section{Characteristics of the study population}

The result showed that $68 \%$ of samples were females and males $32 \%$ and the mean age of children. The occupation of the majority of the samples was student. $87 \%$ respondents claimed to have participated in a culture of eating raw pork warmed under a hot stone.

\section{Prevalence of Taeniasis and soil-transmitted} helminthiasis

A total 132 inhabitants in Banti village were participated in this study. There was no Taenia egg positive through Kato katz examination. Moreover, $60.6 \%$ of them $(80 / 132)$ were positive for eggs of STHs (Ascaris, Trichuris or hookworm) see Table 1

Table 1. Presenting the Prevalence of Taeniasis and STH by age group

\begin{tabular}{ccccccc}
\hline $\begin{array}{c}\text { Age } \\
\text { (years) }\end{array}$ & $\begin{array}{c}\text { No. } \\
\text { examineed }\end{array}$ & $\begin{array}{c}\text { No. of } \\
\text { infected }\end{array}$ & $\begin{array}{c}\text { \%infected } \\
\text { Ma }\end{array}$ & $\begin{array}{c}\text { No. of } \\
\text { infected }\end{array}$ & $\begin{array}{c}\text { Taeniasis } \\
\text { \% infected }\end{array}$ \\
\hline $10-15$ & 29 & 38 & 0 & 0 & 41 & 31.06 \\
$16-30$ & 7 & 27 & 0 & 0 & 23 & 17.42 \\
$31-45$ & 4 & 21 & 0 & 0 & 13 & 9.85 \\
$46+$ & 2 & 4 & 0 & 0 & 3 & 2.27 \\
\hline Total & 42 & 90 & 0 & 0 & 80 & 60.61 \\
\hline
\end{tabular}


For STH infection, the most frequently identified species of A. lumbricoides (34.85\%), Trichiuris trihiura (31.82\%) and hookworm (5.2\%) (Table 2). We found 80 inhabitants with at least one infection of STH $(60,61 \%)$

\begin{tabular}{ccccc} 
& \multicolumn{4}{c}{ Table 2. STH infection by species } \\
\hline \multirow{2}{*}{$\begin{array}{c}\text { Total } \\
\text { Samples }\end{array}$} & $\mathrm{4l}$ & $\mathrm{Tt}$ & $\mathrm{Hw}$ & $\begin{array}{c}\text { Result } \\
\text { no. of Any } \\
\text { infection }\end{array}$ \\
\cline { 2 - 5 } & No. Positive & No. Positive & No. Positive & 80 \\
\hline 132 & 46 & 42 & 7 & 60.61 \\
\hline
\end{tabular}

The Three suspected NCC patients were examined by Computed tomography (CT). Patient's condition presentation can be seen based in brain $\mathrm{CT}$ and leg below.

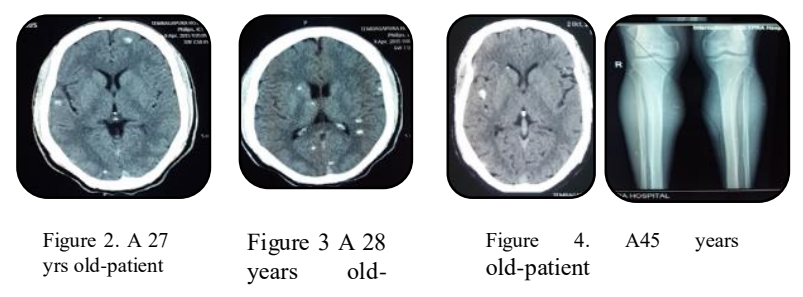

The CT showing multiple calcifications in patients with nodular calcified stage of NCC. CT is better than MRI in depicting the calcified nodule.[8,13] Patient (3) showed disseminated cysticercosis in the leg.

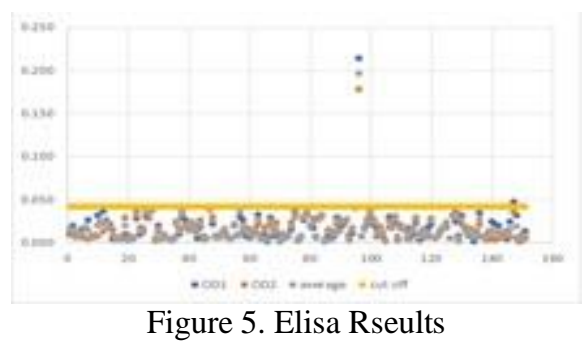

A total 131 serum samples were examined at Departement Parasitology, Faculty of Medicine Udayana University, Denpasar Bali. Based on the result was evaluated by ELISA plate reader using the optical density at $405 \mathrm{~nm}$ (OD405). Serology revealed that one of the 131 serum samples was positive $(0.196$, cut off 0.042$)$

Fifteen of 131 people who were sero-negative showed relatively higher OD values close to the cut-off values. Two from 3 suspected NCC patients included in serum samples for ELISA examination. The three patients result with multiple diagnosis to confirm the diagnosis can be analyze in Table 4.

Table 4. Multiple Diagnosis for NCC

\begin{tabular}{llllcl}
\hline No & Age & Gender & CT & Serology & Diagnosis \\
\hline 1 & 27 & male & Brain CT & $+(0.196)$ & Active NCC \\
2 & 28 & male & Brain CT & $+/-(0.041)$ & Active NCC \\
3 & 45 & male & Brain CT & Not done & Active NCC \& DCC \\
\hline
\end{tabular}

This study showed that soil-transmitted helminth infections are prevalent among inhabitants in Banti village but no taenia ova presence in among inhabitant, Jayaprakash et.al noted that sedimentation, flotation and kato katz test are concentration method but they have low sensitivity for Taenia egg and cannot differentiate between T. Solium and T. saginata. For serology test for T. solium tapeworm stage specific antibody have been advanced as research technique [6].

The serology result presented one suspect of NCC was positive and the other case close to cut off value. Limitation of this study, we cannot examined the third NCC suspect due to patient consent. Several more cases showing OD value $>0.020$ or $>0.030$ may become positive if any further follow up from local public health as a part of surveillance. Human taeniasis is generally asymptomatic, although abdominal discomfort and weight loss have been reported [1]. For further study the specific coproantigen detection by ELISA and PCR will improve the screening for $T$. solium carriers among healthy individuals from endemic areas.[2] $T$. solium taeniasis carriers can possibly contaminate others or as public health treat (or themselves through autoinfection) is particularly troubling when considering that populaces from known T. solium endemic.[19] However, in endemic areas, where environmental exposure to NCC is high, a significant proportion of individuals from the general population will test positive for antibodies despite not having active NCC infection. This can lead to overestimation of NCC prevalence within study populations [20].

The diagnosis of neurocysticercosis is difficult because clinical manifestations are nonspecific, most neuroimaging findings are not pathognomonic. A set of diagnostic criteria was proposed recently revisited based on objective clinical, imaging, immunological, and epidemiological data. [2,7], The present finding shows, the clinical suspicion in patients of endemic areas associated with diagnostic of imagine (CT) and Enzyme Linked ImmunoSorbent Assay (ELISA) contributes to reaching the NCC diagnosis[13].

The three patients participated eating raw pork warmed under hot stones. For patients with only calcified lesions, there was also consensus that there was no role for antiparasitic agents because the cysts are already dead. The recent depiction of contrast enhancement and edema around calcified brain sores driven to talk of whether there will be a part for anti-inflammatory medicine in such patients, but no controlled information exist however [2,7]. Multiple calcifications in patients with nodular calcified stage of NCC of three suspect of NCC with history of epileptic seizures and patient who like living in the area where cysticercosis is still endemic so Sudewi et.al concluded the diagnosis of NCC $[5,14,16]$. Disseminated cysticercosis (DCC) is an unprecedented frame generally detailed in endemic countries. There's broad dissemination of the cysticerci in for all intents and purposes any portion of the body. Signs and symptoms depend upon the area and number of the cysticerci and host's immune respond. Commonly, patients display with extension of the muscles, subcutaneous and lingual nodules [17]. 
Kesehatan Lengkap di Kaki Pegunungan Papua. March27.https://lifestyle.kompas.com/read/2017/03/27/120 315123/rs.waa.banti.fasilitas.kesehatan.lengkap.di.kaki.peg unungan.papua?page $=$ all .

[10] Organization, World Health. 2019 Taeniasis/Cysticercosis. Accessed August 29, 2019 https://www.who.int/zoonoses/diseases/taeniasis/en/.

[11] Rajshekhar, Vedantam. 2016 "Neurocysticercosis: Diagnostic problems \& current therapeutic strategies." Indian J Med Res p 319-326.

[12] RI, Kementerian Kesehatan. 2012. "Profil Kesehatan Kabupaten Mimika Tahun 2012." www.depkes.go.id.

http://www.depkes.go.id/resources/download/profil/PROFI L KAB KOTA 2012/9412 Papua Kab Mimika 2012.pdf

[13] SA, Constantino. 2012. Colegio Interamericano de Radiología. March 13. Accessed August 02, 2019. http://www.webcir.org/revistavirtual/articulos/marzo13/faar dit ing a.pdf.

[14] Sahlu, Ida. 2019. "Estimating the association between being seropositive for cysticercosis and the prevalence of epilepsy and severe chronic headaches in 60 villages of rural Burkina Faso ." PLOS Neglected Tropical Diseases | https://doi.org/10.1371/journal.pntd.0007101.

[15] Sotelo, Julio. 2004. "Neurocysticercosis — Is the Elimination of Parasites Beneficial?" The New England Jornal of Medicine 280-282.

[16] Sudewi, AA Raka et.al. 2013. "A case report of disseminated cysticercosis in Bali, Indonesia." The Indonesian Journal of Infectious Diseases.

[17] Venkat, Bargavee et.al. 23 February 2016. "A comprehensive review of imaging findings in human cysticercosis." Japan Radiological Society.

[18] Wandra, Toni et.al. 2016. "Neurocysticercosis Diagnosed in a Patient with Taenia saginata Taeniasis after Administration of Praziquantel: A Case Study and Review of the Literature." Primary Health Care Volume 6, Issue 3, DOI: 10.4172/2167-1079.1000231.

[19] Wandra, Toni et.al. 2015. "The present situation and towards the prevention and control of neurocysticercosis on the tropical island, Bali, Indonesia." BioMed Central.

[20] Welburn, Lucy B. Gripper and Susan C. 2017. "The causal relationship between neurocysticercosis infection and the development of epilepsy - a systematic review." Infectious Diseases of Poverty BMC DOI 10.1186/s40249-017-0245-y. 